Original Article

\title{
Somatotype and body composition analysis of Korean youth soccer players according to playing position for sports physiotherapy research
}

\author{
Ji-Woong Noh, PT, MS ${ }^{1) a}$, Mee-Young Kim, PT, PhD ${ }^{1) a}$, Lim-Kyu Lee, PT, MS ${ }^{1,2)}$, \\ Byoung-Sun Park, PT, MS ${ }^{1)}$, Seung-Min Yang, PT, MS ${ }^{1)}$, Hye-Joo Jeon, PT, MS ${ }^{1)}$, \\ Won-Deok Lee, PT, MS ${ }^{1)}$, Ju-Hyun Kim, PT, PhD ${ }^{3)}$, Jeong-Uk Lee, PT, PhD ${ }^{4}$, \\ Taek-Yong Kwak, PhD ${ }^{5)}$, Tae-Hyun Lee, PhD ${ }^{6)}$, Ju-Young Kim, $\mathrm{PhD}^{6}$ ), Junghwan Kim, PT, PhD ${ }^{7}$ * \\ 1) Laboratory of Health Science and Nanophysiotherapy, Department of Physical Therapy, Graduate \\ School, Yongin University, Republic of Korea \\ 2) Commercializations Promotion Agency for R\&D Outcomes, Republic of Korea \\ 3) Department of Physical Therapy, College of Health Welfare, Wonkwang Health Science University, \\ Republic of Korea \\ 4) Department of Physical Therapy, College of Health Science, Honam University, Republic of Korea \\ 5) Department of Taekwondo Instructor Education, College of Martial Arts, Yongin University, \\ Republic of Korea \\ 6) Department of Combative Martial Arts Training, College of Martial Arts, Yongin University, \\ Republic of Korea \\ 7) Department of Physical Therapy, College of Public Health and Welfare, Yongin University: Yongin \\ 449-714, Republic of Korea
}

\begin{abstract}
Purpose] The purpose of this study was to investigate the somatotype and physical characteristic differences among elite youth soccer players. [Subjects and Methods] In the present study, we evaluated twenty-two Korean youth soccer players in different playing positions. The playing positions were divided into forward (FW), midfielder (MF), defender (DF), and goalkeeper (GK). The participants' lean body mass (LBM), fat free mass (FFM), fat mass (FM), and basal metabolic rate (BMR) were measured and their somatotype determined according to the Heath-Carter method. [Results] The youth soccer players had twelve ectomorphic, eight mesomorphic, and two central predominant types. The DFs were taller than, but otherwise similar in physical characteristics to the FWs and MFs. The GKs were taller and heavier than the other players; however, their somatotype components were not significantly different. LBM, FFM, and BMR were significantly higher in GKs than in FWs and MFs. Although LBM, FFM, and BMR values between GKs and DFs showed large differences, they were not statistically significant. [Conclusion] The present study may contribute to our understanding of the differences in somatotype and body composition of Korean youth soccer players involved in sports physiotherapy research.

Key words: Korean youth soccer players, Somatotype, Sports physiotherapy
\end{abstract}

(This article was submitted Oct 3, 2014, and was accepted Nov. 28, 2014)

\section{INTRODUCTION}

Soccer is one of the most popular sports in the world. A variety of age groups, from youth to senior, play it ${ }^{1,2)}$. Soccer is a team sport played for at least $80-90$ minutes in official games $^{3)}$. The game requires a high level of skill and stamina, and participants tend to show particular physical and physiological characteristics ${ }^{4}$. Soccer players are divided into four

\footnotetext{
a First two authors (Noh JW and Kim MY) contributed equally to this work.

*Corresponding author. Junghwan Kim (E-mail: junghwankim3@yongin.ac.kr)
}

(C2015 The Society of Physical Therapy Science. Published by IPEC Inc. This is an open-access article distributed under the terms of the Creative Commons Attribution Non-Commercial No Derivatives (by-ncnd) License $<$ http://creativecommons.org/licenses/by-nc-nd/3.0/>. playing positions: forward (FW), midfielder (MF), defender (DF), and goalkeeper (GK). Activity distance and time in soccer competition are different among the playing positions. The GK, in particular, has the lowest activity in the game and the shortest activity distance ${ }^{5)}$. Many studies have examined the different physical and physiological characteristics of soccer players based on playing position ${ }^{3,4,6)}$. Somatotype is determined by the physical characteristics of the body. Heath and Carter determined somatotype by measuring body size, width of bone, and thickness of skin. The basic somatotypes can be further divided into 13 subtypes $^{7-9)}$. The somatotypes of athletes suggest the physical characteristics of their sports ${ }^{10-13)}$. Heath-Carter's classification can be applied to youth soccer players. By evaluating the somatotypes of youth soccer players, the effect of their sport can be seen. This is also true of body composition. Sports players and non-players have different body compositions ${ }^{2,14)}$. Further- 
more, the body compositions of athletes of each sport are different, depending on the characteristics of the sport. The adaptation to physical effort, developed during training and the process of selection, results in a decrease of somatotype and body composition diversity among athletes in similar sports or using similar skills ${ }^{15,16)}$. Therefore, somatotype and body composition is a meaningful characteristic of sports events. A great deal of research is being done on the physical characteristics of soccer players. However, the study of youth soccer players, especially Korean, is limited. Our study measured the physical characteristics of Korean youth soccer players to establish a reference for the study of training and injury rehabilitation of youth soccer players.

\section{SUBJECTS AND METHODS}

The subjects were 22 Korean youth soccer players with no physical or psychological conditions. All the volunteers provided their informed consent prior to participation. Measurements were performed in October 2013. The participants also completed a questionnaire in an individual in-depth interview, which took 20 to 30 minutes per person ${ }^{17)}$. The characteristics of the participants are shown in Table 1. The characteristics of the youth soccer players according to playing position can be found in Fig. 1 and Table 2. The subjects wore only shorts for the measurements, and the measurements were taken by a single person. Before being measured, all participants rested for thirty minutes. First, height and weight were measured. Then the girths (flexed and tensed) of the upper arm and thickest part of the calf were determined with a tape measure. The breadths of the biepicondylar humerus and biepicondylar femur were measured with a large anthropometer. Finally, skinfold thicknesses of the triceps brachii, subscapular, superior iliac, and calf were determined with a medical skinfold caliper (Jamar, USA). Measurement results were used to calculate the somatotype with the modified somatotype method ${ }^{7-9)}$. The somatotypes were classified as endomorphic, mesomorphic, ectomorphic, and balanced types, according to Heath-Carter's modified somatotype method, and further broken down into thirteen subcategories. Balanced endomorphs have a dominant endomorphic component, and the values the mesomorphic and ectomorphic components do not differ by more than 0.5 . Mesomorphic endomorphs have a dominant endomorphic component, and the mesomorphic component is higher than the ectomorphic component. Mesomorph-endomorphs mesomorphic and endomorphic components do not differ by more than 0.5 , and the ectomorphic component is lower than the other values. Endomorphic mesomorphs have a dominant mesomorphic component, and the endomorphic component is higher than the ectomorphic component. Balanced mesomorphs have a dominant mesomorphic component, and the values of the endomorphic and ectomorphic components do not differ by more than 0.5 . Ectomorphic mesomorphs have a dominant mesomorphic component, and the ectomorphic component is higher than the endomorphic component. Mesomorph-ectomorphs by between their mesomorphic and ectomorphic components do not differ by more than 0.5 , and the endomorphic component is lower than the other values. Mesomorphic ectomorphs have a dominant ectomorphic
Table 1. Characteristics of Korean youth soccer players

\begin{tabular}{lc}
\hline Variable & Korean youth soccer players \\
\hline Age (yrs) & $16.3 \pm 0.1$ \\
Gender & \\
Male (\%) & $22(100.0)$ \\
Female (\%) & - \\
Height (cm) & $176.5 \pm 1.0$ \\
Weight (kg) & $68.3 \pm 1.3$ \\
BMI (kg/m $\left.{ }^{2}\right)$ & $21.9 \pm 0.3$ \\
Career (yrs) & $7.1 \pm 0.4$ \\
Training Time & $3.8 \pm 0.3 \mathrm{~h} / \mathrm{day}$ \\
Position & $20.8 \pm 1.6 \mathrm{~h} / \mathrm{week}$ \\
Forward (\%) & $6(27.3)$ \\
Midfielder (\%) & $6(27.3)$ \\
Defender (\%) & $8(36.4)$ \\
Goalkeeper (\%) & $2(9.1)$ \\
Somatotype (Dominant type) & \\
Endomorphy (\%) & - \\
Mesomorphy (\%) & $8(36.4)$ \\
Ectomorphy (\%) & $12(54.5)$ \\
Central (\%) & $2(9.1)$ \\
Endomorphic Component & $2.0 \pm 0.1$ \\
Mesomorphic Component & $2.6 \pm 0.2$ \\
Ectomorphic Component & $3.1 \pm 0.1$ \\
\hline Data are prsentas &
\end{tabular}

Data are presented as means \pm SE. BMI, body mass index

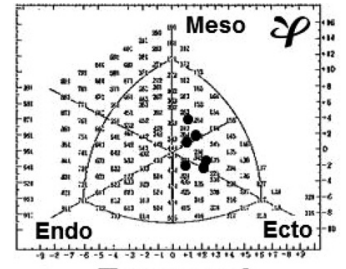

Forward

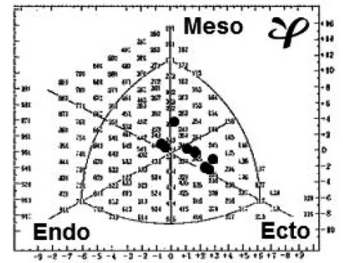

Defender

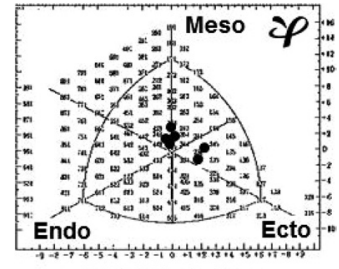

Midfielder

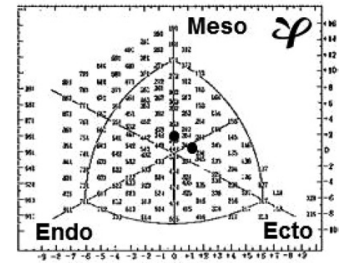

Goalkeeper
Fig. 1. Somatcharts of the playing positions of the elite Korean youth soccer players

Endo, endomorphy; Meso, mesomorphy; Ecto, ectomorph

component, and the mesomorphic component is higher than the endomorphic component. Balanced ectomorphs have a dominant ectomorphic component, and the values of the endomorphic and mesomorphic components do not differ by more than 0.5. Endomorphic ectomorphs have a dominant 
Table 2. Differences in somatotype among the positions of the Korean youth soccer players

\begin{tabular}{|c|c|c|c|c|}
\hline \multirow{2}{*}{ Variable } & \multicolumn{4}{|c|}{ Positions of the Korean youth soccer players } \\
\hline & Forward (FW) & Midfielder (MF) & Defender (DF) & Goalkeeper (GK) \\
\hline Number $(\%)$ & $6(27.3)$ & $6(27.3)$ & $8(36.4)$ & $2(0.9)$ \\
\hline Height (cm) & $173.7 \pm 0.5$ & $174.2 \pm 1.1$ & $177.6 \pm 1.6^{*}$ & $187.0 \pm 1.0^{* \dagger \#}$ \\
\hline Weight (kg) & $64.1 \pm 1.8$ & $67.3 \pm 0.9$ & $68.9 \pm 1.5$ & $81.4 \pm 3.5^{* * \#}$ \\
\hline BMI $\left(\mathrm{kg} / \mathrm{cm}^{2}\right)$ & $21.3 \pm 0.5$ & $22.2 \pm 0.5$ & $21.9 \pm 0.5$ & $23.3 \pm 0.8$ \\
\hline \multicolumn{5}{|l|}{3 Somatotype } \\
\hline Endo $\left(\% \mathrm{a} / \%^{\mathrm{b}}\right)$ & - & - & - & - \\
\hline $\operatorname{Meso}\left(\%{ }^{\mathrm{a}} / \%^{\mathrm{b}}\right)$ & $2(33.3 / 9.1)$ & $3(50.0 / 13.6)$ & $2(25.0 / 9.1)$ & $1(50.0 / 4.5)$ \\
\hline Ecto $\left(\% \mathrm{a} / \%^{\mathrm{b}}\right)$ & $4(66.7 / 18.2)$ & $2(33.3 / 9.1)$ & $5(62.5 / 22.7)$ & $1(50.0 / 4.5)$ \\
\hline Central $\left(\%{ }^{\mathrm{a} /} \%^{\mathrm{b}}\right)$ & - & $1(16.7 / 4.5)$ & $1(12.5 / 4.5)$ & - \\
\hline Endo C. & $1.8 \pm 0.2$ & $2.2 \pm 0.2$ & $1.9 \pm 0.2$ & $2.3 \pm 0.3$ \\
\hline Meso C. & $2.4 \pm 0.3$ & $2.9 \pm 0.2$ & $2.5 \pm 0.3$ & $2.9 \pm 0.5$ \\
\hline Ecto C. & $3.2 \pm 0.2$ & $2.8 \pm 0.3$ & $3.2 \pm 0.3$ & $3.0 \pm 0.3$ \\
\hline \multicolumn{5}{|l|}{13 Somatotype } \\
\hline \multirow[t]{5}{*}{ Types $\left(\%{ }^{\mathrm{a} /} \%^{\mathrm{b}}\right)$} & $\operatorname{BEc} 2(33.3 / 9.1)$ & BM $2(33.3 / 9.1)$ & BEc $3(37.5 / 13.6)$ & BEc $1(50.0 / 4.5)$ \\
\hline & EcM $2(33.3 / 9.1)$ & $\operatorname{BEc} 1(16.7 / 4.5)$ & MEc $2(25.0 / 9.1)$ & BM $1(50.0 / 4.5)$ \\
\hline & MEc $1(16.7 / 4.5)$ & MEc $1(16.7 / 4.5)$ & EcM $1(12.5 / 4.5)$ & \\
\hline & EnEc $1(16.7 / 4.5)$ & EnM $1(16.7 / 4.5)$ & M-En 1 (12.5/4.5) & \\
\hline & & Cen $1(16.7 / 4.5)$ & Cen $1(12.5 / 4.5)$ & \\
\hline
\end{tabular}

Data are presented as the mean \pm SE. aPercentage of athletes in playing position. ${ }^{b}$ Percentage of all participants. BMI, body mass index; Endo C, endomorphic component; Meso C, mesomorphic component; Ecto C. ectomorphic component; BEc, balanced ectomorph; EcM, ectomorphic mesomorph; MEc, mesomorphic ectomorph; EnEc, endomorphic ectomorph; BM, balanced mesomorph; EnM, endomorphic mesomorph; Cen, central type; M-En, mesomorph-endomorph. ${ }^{* * \#}: \mathrm{p}<0.05$.

ectomorphic component, and the endomorphic component is higher than the mesomorphic component. Endomorph-ectomorphs endomorphic and ectomorphic components do not differ by more than 0.5 , and the mesomorphic component is lower than the other values. Ectomorphic endomorphs have a dominant endomorphic component, and the ectomorphic component is higher than the mesomorphic component). Lastly, central types do not differ by more than 1 among the components values $^{7-9)}$.

The Heath-Carter formula using our study is as follows:

1) Endomorphic component

$=-0.7182+0.1451 \times \sum \mathrm{SF}-0.00068 \times \sum \mathrm{SF}^{2}+0.0000014 \times \sum \mathrm{SF}^{3}$

$\sum \mathrm{SF}=$ (sum of skinfold thickness of triceps brachii, subscapular, and superior iliac) $\times[170.18 /$ height $(\mathrm{cm})]$

2) Mesomorphic component

$=0.858 \times$ breadth of biepicondylar humerus $+0.601 \times$ breadth of biepicondylar femur $+0.188 \times$ modified girth of upper arm $+0.161 \times$ modified girth of calf - height $\times 0.131+4.5$

Modified value is [value - (1/10 skinfold thickness)]

3) Ectomorphic component

The ectomorphic component is the difference according to the value of the height-weight ratio (HWR, HWR = height $/ 3 \sqrt{ }$ weight).

$\mathrm{HWR} \geq 40.75=0.732 \times \mathrm{HWR}-28.58$

$38.25<$ HWR $<40.75=0.463 \times$ HWR -17.63

$\operatorname{HWR} \leq 38.25=0.1$

The formula marked on the somatotype chart is as follows:

$\mathrm{X}=$ Ectomorphic component - Endomorphic component

$\mathrm{Y}=2 \times$ Mesomorphic component - (Endomorphic com ponent + Ectomorphic component)

To confirm body composition, a 4-pole-8-pole contact electrical method was used ${ }^{2,14)}$. The lean body mass, fat free mass, fat mass, and basal metabolic rate of the participants were measured using a precision body composition analyzer (InBody 520, Biospace, Korea). Participants were measured in a standing position with both arms abducted.

Statistical analyses were conducted using the SAS software (version 6.12) to calculate averages and standard deviations. The data were expressed as mean \pm standard error (SE) of the measurements. A significance level of $\alpha=0.05$ was chosen when performing the independent $t$-test for group comparisons. The protocol for this study was approved by 
Table 3. Differences in body composition among the positions of the Korean youth soccer players

\begin{tabular}{lcccc}
\hline \multirow{2}{*}{ Variable } & \multicolumn{4}{c}{ Positions of the Korean youth soccer players } \\
\cline { 2 - 5 } & Forward (FW) & Midfielder (MF) & Defender (DF) & Goalkeeper (GK) \\
\hline LBM (kg) & $35.5 \pm 1.3$ & $36.7 \pm 0.5$ & $38.2 \pm 0.9$ & $45.6 \pm 2.3^{* \dagger}$ \\
FFM (kg) & $61.5 \pm 1.9$ & $63.6 \pm 0.7$ & $65.9 \pm 1.5$ & $78.5 \pm 3.7^{* \#}$ \\
FM (kg) & $2.6 \pm 0.4$ & $3.7 \pm 0.6$ & $3.0 \pm 0.5$ & $3.0 \pm 0.2$ \\
BF (\%) & $4.0 \pm 0.6$ & $5.5 \pm 0.9$ & $4.4 \pm 0.7$ & $3.7 \pm 0.4$ \\
BMR (Kcal) & $1,698.8 \pm 42.1$ & $1,743.0 \pm 16.3$ & $1,793.8 \pm 33.2$ & $2,064.0 \pm 79.0^{* \#}$ \\
\hline
\end{tabular}

Data are presented as the mean \pm SE. LBM, lean body mass; FFM, fat-free mass; FM, fat mass; BF, body fat; BMR, basal metabolism rate. ${ }^{* \dagger \#: ~} \mathrm{p}<0.05$.

the Committee of Ethics in Research of the University of Yongin, in accordance with the terms of Resolution 5-1-20, December 2006.

\section{RESULTS}

The general characteristics of the twenty-two youth soccer players are noted in Table 1 . Some variation in the characteristics of somatotype was observed among the playing positions (Table 2). The DFs were taller than the FWs and MFs, but had physical characteristics similar to the other field players. While GKs were taller and heavier than the other players their somatotype components were not significantly different from those of the other players (Table 2 ). On the somatotype chart, the subjects are all located slightly to the left side (the ectomorphic side), regardless of the players' positions (Fig. 1). The participants consisted of twelve ectomorphic, eight mesomorphic, and two central predominant types. Subdividing the youth soccer player's somatotypes resulted in seven balanced ectomorphs, four mesomorphic ectomorphs, three ectomorphic mesomorphs, three balanced mesomorphs, two central types, one endomorphic ectomorph, one endomorphic mesomorph, and one mesomorph-endomorph (Table 2). Body composition results were not different in terms of somatotypes. LBM, FFM, $\mathrm{FM}, \mathrm{BF}$, and BMR were not significantly different among the field players. However, LBM, FFM, and BMR were significantly higher in GKs than in FWs and MFs (Table 3). LBM, FFM, and BMR values among GKs and DFs showed large differences but they were not statistically significant (Table 3).

\section{DISCUSSION}

We compared the somatotypes and body compositions of Korean youth soccer players according to their playing positions. The DFs were taller than the other field players, but they were similar in other physical characteristics. The GKs had higher values of height, weight, LBM, FFM, and BMR than the other players; however, the BMI and somatotype components were not significantly different among the positions. Although the GKs were taller and more muscular than the other players, the ratio of their height to muscle was similar to that of the other positions. As a result, their somatotype components were not different from those of the other players. The subjects had predominantly ectomorphic and mesomorphic somatotypes. According to our data, the somatotype components were not different among the playing positions, but FWs and DFs had a greater difference between the ectomorphic and mesomorphic components. Thus, FWs and DFs were more likely to have a thin body type than MFs and GKs. Soccer players rely heavily on aerobic endurance due to the game's intermittent high intensity activity ${ }^{4)}$. As a result, soccer players tend to have low body fat. Our study showed that all the subjects had low body fat, and it was very low in comparison with non-players. According to a study of obesity in male Asian college students, their body fat mass averaged $14.26 \mathrm{~kg}$, and their percentage of body fat had a mean of $18.86 \%{ }^{18)}$. While obesity rates are increasing, the typical Korean youth soccer player has very lean body characteristics. Studies of somatotype and physical characteristics of adult soccer players have reported that soccer players have a mesomorphic predominant somatotype ${ }^{3,4,19)}$. More than half the participants in our study had an ectomorphic predominant somatotype, and the remaining players had mostly mesomorphic body types, likely because youth soccer players have not reached their full growth. Another study of young soccer players showed that they had a higher ectomorphic component value than older age groups ${ }^{20)}$. It has also been reported that adult soccer players have obviously different physical characteristics according to playing position $^{6,21)}$. This is also seen in other ball games. Handball and basketball players have different physical characteristics for each playing position ${ }^{22,23)}$. However, the physical characteristics of youth soccer players in this study had no significant differences, except for the GKs. Thus, young field players should be able to change their position more easily than adult players. In fact, players frequently change position in youth soccer teams. Similar results were reported for the somatotypes and physical characteristics of Zimbabwean youth soccer players ${ }^{24)}$. However, the subjects in the current study were taller than those in the Zimbabwean study. Thus, the Zimbabwean youth soccer players had a higher mesomorphic component than the Korean youth soccer players, despite the Korean youths having a higher FFM value than the Zimbabwean youths. The Korean youth soccer players had ectomorphic and mesomorphic predominant somatotypes and very low body fat for their athletic performance. According to a study of minimizing injury rate in soccer players by somatotype, the injury rate of mesomorphic play- 
ers is less than that of ectomorphic players ${ }^{25}$. Therefore, fat reduction and increased skeletal muscle mass would be beneficial for the safety of the young soccer players. In summary, Korean youth soccer players tend to have lean builds with predominantly ectomorphic and mesomorphic somatotypes while adult soccer players have a predominantly mesomorphic somatotype. This allows younger soccer players more flexibility over the position they play than adult players. In addition, the injury rate of mesomorphic players is less than that of ectomorphic players, so the somatotype of the players should be considered during training. According to our data, we suggest that youth soccer players focus on reducing fat and building up skeletal muscle to prevent injury and aid in recovery. This study provides reference data of the physical characteristics of youth soccer players, but further research is needed to assist in the proper training of athletes returning from injury, and to support sports physiotherapy research.

\section{REFERENCES}

1) Jooste J, Steyn BJ, Van den Berg L: Psychological skills, playing position and performance of African youth soccer teams. SAJR SPER, 2014, 36 85-100.

2) Yang SM, Lee WD, Kim JH, et al.: Differences in body components and electrical characteristics between youth soccer players and non-athletes. Health, 2013, 5: 1010-1015. [CrossRef]

3) Orhan O, Sagir M, Zorba E: Comparison of somatotype values of footbal players in two professional league football teams according to the positions. Coll Antropol, 2013, 37: 401-405. [Medline]

4) Hazir T: Physical characteristics and somatotype of soccer players according to playing level and position. J Hum Kinet, 2010, 26: 83-95. [CrossRef]

5) Clemente FM, Couceiro MS, Martins FM, et al.: Activity profiles of soccer players during the 2010 world cup. J Hum Kinet, 2013, 38: 201-211. [Medline] [CrossRef]

6) Henríquez-Olguín C, Báez E, Ramírez-Campillo R, et al.: Somatotype profile of professional male soccer Chilean players. Int J Morphol, 2013, 31: $225-230$.

7) Heath BH, Carter JE: A comparison of somatotype methods. Am J Phys Anthropol, 1966, 24: 87-99. [Medline] [CrossRef]

8) Heath BH, Carter JE: A modified somatotype method. Am J Phys Anthropol, 1967, 27: 57-74. [Medline] [CrossRef]

9) Heath BH, Carter JE: Growth and somatotype patterns of Manus children, territory of Papua and New Guinea: application of a modified somatotype method to the study of growth patterns. Am J Phys Anthropol, 1971, 35 : 49-67. [Medline] [CrossRef]

10) Noh JW, Kim JH, Kim J: Somatotype analysis of Korean wrestling athletes compared with non-athletes for sports health sciences. Toxicol Environ Health Sci, 2013a, 5: 163-168. [CrossRef]

11) Noh JW, Kim JH, Kim J: Somatotype analysis of elite taekwondo athletes compared with non-athletes for sports health sciences. Toxicol Environ Health Sci, 2013b, 5: 189-196. [CrossRef]

12) Noh JW, Kim JH, Kim MY, et al.: Somatotype analysis of elite boxing athletes compared with nonathletes for sports physiotherapy. J Phys Ther Sci, 2014a, 26: 1231-1235. [Medline] [CrossRef]

13) Noh JW, Kim JH, Kim J: Somatotype analysis of elite judo athletes compared with non-athletes for sports health sciences. Toxicol Environ Health Sci, 2014b, 6: 99-105. [CrossRef]

14) Lee WD, Lee LK, Kim B, et al.: Differences in body components and the significance of rehabilitation for taekwondo athletes compared to nonathletes. Toxicol Environ Health Sci, 2012, 4: 203-208. [CrossRef]

15) Charzewski J, Glaz A, Kuzmicki S: Somatotype characteristics of elite European wrestlers. Biol Sport, 1991, 8: 213-221.

16) Krawczyk B, Sklad M, Jackiewicz A: Heath-Carter somatotypes of athletes representing various sports. Biol Sport, 1997, 14: 243-250.

17) Kim JH, Kim IH, Lee JU, et al.: Change of muscular activity and dynamic stability of the knee joint due to excessive and repetitive jumping or cutting by female athletes. J Phys Ther Sci, 2012, 24: 715-719. [CrossRef]

18) Carpenter CL, Yan E, Chen S, et al.: Body fat and body-mass index among a multiethnic sample of college-age men and women. J Obes, 2013, 2013: 790654. [Medline] [CrossRef]

19) Nikolaidis PT, Vassilios Karydis N: Physique and body composition in soccer players across adolescence. Asian J Sports Med, 2011, 2: 75-82. [Medline]

20) Gil SM, Gil J, Ruiz F, et al.: Anthropometrical characteristics and somatotype of young soccer players and their comparison with the general population. Biol Sport, 2010, 27: 17-24. [CrossRef]

21) Gonçalves BV, Figueira BE, Maçãs V, et al.: Effect of player position on movement behaviour, physical and physiological performances during an 11-a-side football game. J Sports Sci, 2014, 32: 191-199. [Medline] [CrossRef]

22) Vila H, Manchado C, Rodriguez N, et al.: Anthropometric profile, vertical jump, and throwing velocity in elite female handball players by playing positions. J Strength Cond Res, 2012, 26: 2146-2155. [Medline] [CrossRef]

23) Boone J, Bourgois J: Morphological and physiological profile of elite basketball players in Belgian. Int J Sports Physiol Perform, 2013, 8: 630-638. [Medline]

24) Masocha V, Katanha A: Anthropometry and somatotype characteristics of male provincial youth league soccer players in Zimbabwe according to playing positions. IJSR, 2014, 3: 554-557.

25) Salokun SO: Minimizing injury rates in soccer through preselection of players by somatotypes. J Sports Med Phys Fitness, 1994, 34: 64-69. [Medline] 